Article

\title{
Newcomer Children: Experiences of Inclusion and Exclusion, and Their Outcomes
}

\author{
Jacqueline Oxman-Martinez ${ }^{1, *}$ and Ye Ri Choi ${ }^{2}$ \\ ${ }^{1}$ School of Social Work, University of Montreal, Verdun, QC, H3E 2B7, Canada; E-Mail: jacqueline.oxman- \\ martinez@umontreal.ca; Tel.: +1-514-766-0337 \\ ${ }^{2}$ School of Social Work, McGill University, Montreal, QC, H3A 2A7, Canada; E-Mail: ye.choi@mail.mcgill.ca; \\ Tel.: +1-514-982-6024 \\ * Corresponding author
}

Submitted: 10 July 2014 | In Revised Form: 8 October 2014 | Accepted: 21 November 2014 | Published: 27 November 2014

\begin{abstract}
This article explores the potential inclusion and exclusion factors affecting the developmental outcomes of immigrant children, and examines the influence of inclusive school environment, social/psychological isolation, and perceived discrimination by peers and teachers on the psychosocial and academic adjustment of immigrant children. Our study is based on a subset of data from the New Canadian Children and Youth Study (NCCYS), a national longitudinal survey including 515 foreign-born immigrant children (11 to 13 years) from three ethnic groups (Mainland China, Hong Kong, the Philippines) living in the Montreal and Toronto metropolitan areas, Canada. The results show that after controlling for socio-demographic background variables, teachers' discriminatory attitudes and psychological isolation contribute to the prediction of risk for immigrant children's self-esteem, social competence, and academic performance. Inclusive school environment has a significant effect on social competence and academic performance of immigrant children. Peer discrimination is also associated with self-esteem and social competence. These findings suggest that inclusive school environment, social/psychological isolation, and discrimination are critical factors affecting the developmental outcomes of immigrant children that, in turn, are connected to future prospects for their eventual inclusion and participation in other social, economic, and political venues of the host country.
\end{abstract}

\section{Keywords}

immigrant children; discrimination; psychological isolation; school environment; social isolation

\section{Issue}

This article is part of a regular issue of Social Inclusion, edited by Professor Ulf R. Hedetoft (University of Copenhagen, Denmark).

(C) 2014 by the authors; licensee Cogitatio (Lisbon, Portugal). This article is licensed under a Creative Commons Attribution 4.0 International License (CC BY).

\section{Introduction}

For immigrant children, the experience of migration comprises uncertainty and significant changes in the socio-cultural, physical, and psychological aspects of their lives. It is related to the issues about what it means to belong to and thus to be included in or excluded from particular social settings. This article explores the experiences of new comer immigrant children and their parents in relation to social inclusion and exclusion within the school context through their own accounts.

Much previous research involving children's social inclusion and exclusion has mainly focused on adultcentred approach with children recognized as passive recipients of economic and social resources of their parents (Jackson \& Scott, 2002; Mejer \& Siermann, 2000; Micklewright \& Stewart, 2000). The conditions for social inclusion or exclusion of children have been determined mostly by the circumstances of their fami- 
lies, particularly parents, in terms of family structure, income, and employment status. While it is important to understand how children are included or excluded based on adult-constructed concepts of inclusion, it is also critical to look beyond the adult-focused models or family poverty-focused models (Micklewright, 2002; Phipps \& Curtis, 2001; Ridge, 2002). The importance of a children's perspective is reflected clearly in Article 12 of the 1989 UN Convention on the Rights of the Child as follows: "all children are capable of expressing their own views; children should have the right to express their views in all matters affecting them and; children's views should be taken seriously in accordance with their age and maturity" (United Nations Human Rights, n.d., p. 4). It is imperative that children's own experiences are not rendered invisible by concentrating purely on the needs of parents or families.

There are some studies involving children in expressing their views of social inclusion and exclusion. According to the study conducted by the Canadian Council on Children and Youth (Canadian Council on Social Development, 2002), the focus group with children reported that social inclusion was related to the context of participating in and contributing to their community. They described the concept of social inclusion as having a significant attachment to people, specifically a group of friends and peers. Another Canadian research conducted by Frazee (2003) found that social inclusion was defined by the youth group in terms of participating, being understood, being accepted, and belonging. As revealed by these studies, social interactions and social relationships are key factors for children and youth to describe the concepts of social inclusion and exclusion.

Furthermore it is also important to examine children's experiences from a developmental perspective. This article includes a sample of immigrant children in the transitional period from childhood to adolescence. The establishment of identity is a major developmental task for all youth (Broderick \& Blewitt, 2006). Identity lays the foundation for how individuals view themselves and their future prospects. As part of the life course of immigrant children, identity processes are defined specifically by how individuals make meaning of their own experiences, and by the contexts they encounter at multiple levels including families and schools (Spencer, 2001; Spencer, Swanson, \& Cunningham, 1991). The study of social inclusion and exclusion at school experienced by immigrant children in this transitional period can lead to insights into the factors that promote healthy social and academic adjustment.

The current article attempts to frame children's experiences of social inclusion and exclusion in their daily lives at school from children's own perspective-what they think of the concepts of inclusion and exclusion, and how these experiences affect their outcomes. Four potential factors are analyzed in relation to social in- clusion and exclusion that children may face in their new educational settings: social isolation (lack of social group participation), psychological isolation (feelings of disconnectedness from others), perceived peer discrimination (being rejected by peers), and perceived teacher discrimination (being rejected by teachers). The perception of inclusive school environment reported by parents is added to children's experiences since schools are significant social sites of immigrant family adaptation, including parents as well as their children. This article also examines whether the factors of inclusion/exclusion and children's outcomes are different between the two settlement cities selected in Canada: Montreal and Toronto. A broader description of study objectives is presented after the study background.

\section{Study Background}

\subsection{Social Isolation and Psychological Isolation}

For immigrant children, schools are the most critical arena in which their development and major social interactions occur with profound consequences for their adaptation to the host society. However, newcomer children often face the significant differences of educational settings between their original countries and the host countries. As compared to native-born children, they encounter additional challenges related to school adaptation and social adjustment due to conflict between school and home cultural values, linguistic mastery of receiving country language (Duffy, 2003; Rummens, Tilleczek, Boydell, \& Ferguson, 2008), and acculturation processes (Brown et al., 2013; Nigbur et al., 2008). For newcomer children, a main factor involved in the adaptation process of the new social settings is the social relationships with significant others such as peers and teachers (Fuligni, 1998; SuarezOrozco, Suarez-Orozco, \& Todorova, 2008). Social relationships play a critical role in the growth of sense of belonging as members of social groups as well as in the development of secure social identity and social skills. With respect to the children's experiences of social exclusion at school, the current article focuses on two aspects: first, social isolation which is defined as the lack of opportunities to participate in social group activities with their peers and; second, psychological isolation which refers to feelings of disconnectedness from others, including peers and teachers.

To promote positive peer interactions of immigrant children, participating in social groups provide opportunities to learn new kinds of pro-social skills, to develop new value systems through mutual interactions among group members, and to gain acceptance into new peer groups (Chen, Chang, He, \& Liu, 2005). Previous studies indicated that peer interactions serve as buffers to loneliness and as bolsterers of selfconfidence and self-efficacy providing emotional sus- 
tenance (Gibson, Gandara, \& Koyama, 2004; SuarezOrozco et al., 2008; Way \& Phal, 2001) that supports the development of significant psychological competencies. In contrast, negative peer interactions are associated with poor academic performance and a range of harmful psychological consequences such as low self-esteem and social anxiety (Juvonen \& Graham, 2001; Kochenderfer \& Ladd, 1996; Suarez-Orozco, Pimentel, \& Martin, 2009). Social group engagement can be beneficial where group members share similar values and obligations in terms of academic achievement, and may provide aspiration for children. The study on Asian-American children (Zhou \& Kim, 2006) demonstrated that the academic success of immigrant children is related to the social group engagement in the provision of academic enrichment.

Connections with caring teachers and adults at school can be an important protective factor for immigrant children's psychological isolation. These social relationships can provide immigrant youth with compensatory attachments, critical encouragement, information about new cultural norms, practices, and tools vital to success in school (Roffman, Suárez-Orozco, \& Rhodes, 2003; Suarez-Orozco et al., 2008, 2009). Research on relationships with teachers demonstrated that children showed better health outcomes and higher levels of self-esteem when they felt cared for and understood by their teachers (DuBois \& Silverthorn, 2005). Crosnoe, Johnson and Elder (2004) found that stronger teacher-student bonding in school was related to higher academic achievement for Hispanic American girls. Other studies (LaRusso, Romer, \& Selman, 2008; Suarez-Orozco et al., 2009) also indicated that children who felt rejected by teachers were more likely to disengage from school, thereby jeopardizing their emotional adjustment and academic achievement.

\subsection{Perceived Discrimination by Peers and Teachers}

Discrimination is a salient stressor that immigrant families encounter after migration. At school, discrimination expressed by teachers and other students is a significant source of social exclusion (Micklewright, 2002). With regard to social exclusion by peers, ethnic discrimination can be expressed in many different ways. Peer victimization is an example of types of discrimination among children and youth at school. Peer victimization based on one's ethnic group membership tends to be interpreted as peer discrimination (Verkuyten, Kinket, \& Wielen, 1997). This article focuses on ethnic victimization based on one's ethnicity rather than personal victimization. Verkuyten et al. (1997) refer specifically to those situations where negative peer experiences are related to children's ethnic group membership. Peer victimization can take many different forms and ranges from overt behaviour such as physical and verbal aggression (bullying) to indirect forms, for instance, ignoring or spreading rumours about the victimized child. Previous studies of perceived discrimination have focused on the relationship between psychological outcomes and the prevalence of discrimination towards children from diverse ethnic background. Social rejection and exclusion from significant others are connected to self-doubts and produce low self-esteem, while social acceptance is associated with selfconfidence and produce high self-esteem (Leary \& Baumeister, 2000). Graham's study (2006) revealed that children who perceive high levels of peer ethnic victimization based on one's ethnic background, experience psychological distress such as self-blaming attributions. Oppendal, Roysamb and Heyerdahl (2005) found that perceived discrimination reported by first generation youths was a significant predictor of emotional problems. Such existing evidence about the effects of negative peer experience on self-esteem suggests that perceived discrimination may influence other adaptive social outcomes such as pro-social behavior and social skills (Fisher, Wallace, \& Fenton, 2000; Mounts \& Steinberg, 1995). In recent research with data from the national longitudinal study of immigrant children and youth in Canada, Oxman-Martinez et al. (2012) demonstrated the link between perceived discrimination and negative outcomes such as low selfesteem and less social competence.

Research on academic adjustment of immigrant students (Suarez-Orozco et al., 2009) suggested that students belonging to ethnic minority groups experienced negative ethnic stereotypes and diminished academic expectations by teachers and other staff because of their ethnic background. Mansouri and Kamp (2007) found that perceived discrimination was related to negative consequences in educational outcomes among immigrant groups, suggesting that some immigrant children experienced considerable disadvantage in school, particularly related to discrimination or "racism" practiced by teachers. It also showed that these negative social experiences are associated with lower student achievement. As well, perceived discrimination from teachers has been found to predict lower grades and negative academic self-concept (Davison, Guerrero, Barajas, \& Thomas, 1999).

\subsection{Parental Perceptions of School Environment}

Discourses associated with notions of inclusion and exclusion in formal educational schooling have been documented by an increasing number of scholars (Ainscow, 1999; De Haan, 1999; Dei et al., 2000; Evans et al., 2001; Klasen, 2000). As social inclusion is understood with particular reference to students from diverse minority groups, Dei et al. (2000) define an inclusive school as one in which "every student is able to connect with the school's social environment, cultural and organizational life". Research on educating immi- 
grant students (Rong \& Preissle, 1998; Suarez-Orozco et al., 2008; Suarez-Orozco \& Suarez-Orozco, 2001) highlights the following significant factors related to inclusive school environment for immigrant families: welcoming attitudes created by school policies and staff; high academic expectations for all children regardless of their backgrounds that facilitate students' academic engagement and success in school; respect for heritage cultures and languages; and an emotionally and physically safe school climate. Therefore, within these inclusive school contexts, immigrant students seem to feel proud of their school and enjoy their school lives.

There are migration-related issues that may contribute to immigrant parents' perceptions of their children's school environment: a limited knowledge of how the host educational system works; cultural differences in expectations between immigrant families and schools; and a misunderstanding arising from language issues and customs. Accordingly, in many cases, immigrant parents are often less involved in schools, as indicated by previous research (Carreon, Drake, \& Barton, 2005; Ramirez, 2003; Schofield, 2006). Carreon et al.'s study (2005) showed the negative experiences of parents' interactions with schools: feelings of exclusion from school activities, communication difficulties with school staff, and a sense that their contributions were not valued. The possible dissonance between immigrant families and the educational environment may increase the risk of disengagement in schools which, in turn, negatively influence children's psychosocial and academic adjustment.

For foreign-born immigrant children and their parents, parental perception of inclusive school environment may be particularly significant in relation to children's experiences of social inclusion/exclusion and their outcomes. Immigrant families including both parents and their children concurrently face similar resettlement challenges such as adaptation and acculturation to the new social settings. As the school is one of the major social institutions encountered outside their homes, immigrant parents' perceptions of school environment may provide additional information regarding the levels of social inclusion or exclusion at schools. While there has been bare research attention to the relation between parental perception of school environment and children's adjustment, a recent study on immigrant parents' school perception and their children's adjustment (Hamilton et al., 2011) revealed that parental negative perception of school environment was associated with children's emotional distress and physical aggression.

\subsection{Differential Regional Effects on Children's Experiences of Social Inclusion and Exclusion, and Outcomes}

This study examines whether the factors of inclu- sion/exclusion and children's outcomes are different between the two urban settlement cities selected in Canada: the greater Montreal (Quebec) and the Toronto (Ontario) areas. While Canada is a multicultural country, the Federal Canadian policy of multiculturalism is supplemented by provincial and municipal policies, including those in Quebec (Montreal) and Ontario (Toronto). Quebec differs from the other provinces, focusing on the policy of interculturalism rather than multiculturalism (Barett, 2014). It is characterized as essentially multicultural and diverse, but only under the framework that establishes French as the public language (Alain-Gustave \& lacovino, 2008). Although the Quebec policy emphasize the main components of multiculturalism - heritage cultural maintenance and the encouragement of full social participation by all ethno-cultural communities, French language and culture are given a privileged status (Bouchard \& Taylor, 2008). There are two main grounds addressed in the current article that contribute to making differences in the experiences of inclusion and exclusion between these two regions: first, immigration policies and practices, and second, educational policies and practices. In terms of immigrant policies, while the government of Canada is responsible for determining national standards and objectives for immigration across all provinces including Quebec and Ontario, under the 1991 CanadaQuebec Accord, the Canadian federal government and the Quebec government share the responsibilities for immigration to Quebec (Citizenship and Immigration Canada, 2006). The government of Quebec has the right to select most immigrants destined to the Quebec province and is responsible for the linguistic and cultural integration of permanent residents. Given the different approaches of immigration policies and practices between Quebec and Ontario, it is expected that migration experiences of immigrant families in terms of social inclusion and exclusion may vary across regions. Moreover, federal-provincial division of responsibility for resettlement can be a source of inequity. Although the federal Immigrant Settlement and Adaptation Program provides funding for settlement programs, the amount of money spent per immigrant varies widely from province to province (Ministry of Supply and Services, 1988). Inequities translate into differential access to language training, day care, job training programs and health services, each of which may affect the adaptation of migrant parents and their children. With regard to education, Section 93 of the Constitution Act of 1867 designated education as a matter of provincial jurisdiction, considering an essential condition to protect regional cultural identities (Government of Canada, n.d.). The Constitution Act of 1867 outlined the distribution of power between the federal government and provincial governments. As a result, there is a great deal of variation in Canada in the regulation of education among the provinces. 


\section{Study Objectives}

Existing research has identified a number of factors that contribute to immigrant children' psychosocial and academic adjustment. However, very limited attention has been given to the importance of framing experiences of social inclusion and exclusion within the school context mainly based on the child-perspective in particular for first-generation immigrant children in early adolescence whose experiences and perceptions may be different from other children. The current article seeks to address this gap.

It first explores the potential inclusion and exclusion factors from the perspective of the child that may affect children's outcomes: social isolation, psychological isolation, perceived peer discrimination, and perceived teacher discrimination. In addition, given the fact that first-generation immigrant parents and their children simultaneously go through adaptation processes in the host society including educational settings, parental perception of inclusive school environment is examined as a predictor of inclusion and exclusion experiences in relation to children's outcomes. Secondly it analyses the influence of the potential inclusion and exclusion factors on children's self-esteem, social competence and academic grades. Finally, it investigates whether the factors of inclusion/exclusion and children's outcomes are different between the two settlement cities: the greater Montreal (Quebec) and Toronto (Ontario) areas.

\section{Methods}

\subsection{Data}

The current study is based on a subset of data from the New Canadian Children and Youth Study (NCCYS), a national longitudinal survey of the health and well-being of approximately 4,000 immigrant children living in Montreal, Toronto, the Prairies (Winnipeg, Edmonton, Calgary), and Vancouver in Canada (Beiser et al., 2010). Children participating in the survey were either foreign-born or Canadian-born into families in which at least one parent had immigrated to Canada within the ten years preceding the study's beginnings. They were also in one of two age-defined inception cohorts at the time of the survey: 4-6 years and 11-13 years of age.

Our article focuses on a sub-sample of the full survey, with 515 foreign-born immigrant children (11 to 13 years) from three ethnic groups (Mainland China, Hong Kong, the Philippines) living in the Montreal and Toronto metropolitan areas, Canada. These three Asian groups were selected as the national-level samples of the NCCYS across all sites because, during the decades preceding the initiation of the NCCYS, they were the leading source countries for Canadian immigration (Beiser et al., 2010; Citizenship and Immigration Cana- da, n.d.). The Montreal and Toronto metropolitan areas represented at the research period, the Canada's largest urban areas that had the highest proportion of foreign-born population (Chui, Tran, \& Maheux, 2007). From the sample of this article, $65.4 \%$ were recent newcomers (less than 5 years in Canada).

\subsection{Sampling and Procedures}

The NCCYS used respondent-driven snowball sampling strategies in order to identify hard-to-reach and highly mobile immigrant populations during the beginning years of resettlement (further details of the study design available in Beiser et al., 2010). Representatives from each of the targeted ethno-cultural communities in each city were invited to become members of Community Advisory Councils (CAC). After identifying families from their respective communities who fit NCCYS inclusion criteria (a. length of time in Canada-less than 10 years; and $b$. two age cohorts -4 to 6 years old or 11 to 13 years old), CAC members contacted potential sample families to request permission to introduce a research team member to explain the study and to obtain written consent to participate. Interviews were conducted by bilingual interviewers in the home of the family and took approximately 2 to 3 hours. The NCCYS received ethics approval from the universities involved in the research, including University of Montreal and McGill University in Montreal and University of Toronto in Toronto in order to cover the greater Montreal and Toronto areas.

\subsection{Instruments and Measures}

Structured interview instruments were used to complete the NCCYS survey, including five questionnaires developed by the New Canadian Children and Youth Study (NCCYS) and the National Longitudinal Survey of Children and Youth (NLSCY): Demographic Information, Parent about Family, Parent about Child, Child about Child, and Child Identity. Standard back- translation procedures were utilized to ensure cultural equivalence of concepts in the different languages of the study. All questionnaires were translated from English to each of the heritage languages (i.e., Mandarin, Cantonese, and Tagalog). The project team consulted with the specifically formed Ethno-cultural Community Advisory Councils for the appropriateness of questions as well as language.

The variables used in the current article were drawn from the following questionnaires completed by two informants, the child and the person most knowledgeable (PMK) about the child (mostly the mother): Demographic Information (DI), Parent about Family (PAF), and Parent about Child (PAC) reported by PMK; and Child about Child (CAC) reported by the children themselves aged $11-13$ years. 


\subsubsection{Dependent Variables}

Three dependent variables were used to measure children's psychosocial functioning and academic performance: self-esteem, social competence, and academic grades.

Children's self-esteem was assessed using a fouritem index measure (derived from the CAC questionnaire): I like the way I am; I have a lot to be proud of; a lot of things about me are good; and when I do something, I do it well. The self- esteem measure is a subscale of the General-Self Scale of the Marsh SelfDescription Questionnaire developed by Marsh (Marsh, 1988). Each item has four response categories from $0 . n e v e r$ to 3.most of the time. The reliability coefficient (Cronbach's alpha) for this scale is $\mathbf{0 . 8 2}$. Higher scores indicate a greater sense of positive self-esteem.

Social competence was measured by utilizing the social acceptance and close friendship scale derived from two sources, the Peer Relationships Subscale (Marsh, 1988) and the study by Beiser et al. (1993). It consists of four statements (derived from the CAC questionnaire): I have a lot of friends; I get along easily with others my age; others my age want me to be their friend; and most others my age like me. Each item has four response categories from 0.strongly disagree to 3.strongly agree. Its reliability coefficient is 0.74 . Higher scores represent higher levels of social competence.

Academic grades (Grade Point Averages derived from the CAC questionnaire) were used to assess children's academic performance. Children's factual grades were reported in either letter grades or percentages. These grades were transformed to a ten-point Likert scale from 1 . F or $<50 \%$ to 10 . A or $>90 \%$.

\subsubsection{Independent Variables}

Inclusive school environment was assessed using a sixitem index measure (derived from the PAC questionnaire) (Beiser et al., 2010): parents are made to feel welcome in this school; this school offers parents opportunities to be involved in school activities; children are very proud of their school; most children in this school enjoy being there; getting good grades is very important at this school; children are safe in this school. Response choices ranged from 0. strongly disagree to 4 .strongly agree. The reliability coefficient for this scale is 0.75 .

The social isolation scale (derived from the CAC) contains four items asking how often the child participated in organized groups such as sports, music groups or lessons outside of class, community/church or other religious groups. Responses from each item ranged from 0.never to 3.two or three times a week. They were transformed into a dummy variable, coded as either 0.not socially isolated (participating in any organized groups) or 1.socially isolated (never participating in any organized groups).
Psychological isolation (derived from the CAC) was measured by a single question about the child's feeling of psychological isolation or exclusion at school: the child feels like an outsider or left out of things at school. It has a five-point Likert scale, ranging from 0. never to 4 .all the time.

Perceived peer discrimination was measured by two statements of youth's discrimination experiences (derived from the CAC questionnaire), asking whether they felt that they had been treated unfairly by peers: by other students at school in direct forms of hostile behaviours (hitting, name-calling, pushing, being insulted in front of people, threatening) and; by other students at school in indirect forms of hostile behaviours (ignoring, excluding in social interaction). For children respondents, to facilitate understanding of discrimination experiences, the discrimination questions were preceded by the following introduction: "People sometimes get treated unfairly because of who they are-I mean because they look different, were born outside of Canada, speak with an accent, or because of the color of their skin. I want you to think about the last month and tell me whether you were treated unfairly because of who you are". Each item contains five response choices from 0 .never to 4 .all the time. It has a Cronbach alpha coefficient of 0.67.

Perceived discrimination by teachers (derived from the CAC) was used to measure discriminatory attitudes or behaviours by teachers towards their students. It has three items related to physical appearance and language of children with immigrant background: my teachers in general treat me fairly; my teachers generally treat children equally regardless of how they look; and my teachers generally treat children equally regardless of how they speak. Each item has five response categories from 0 .all the time to 4 .never. The reliability coefficient is 0.74 .

\subsubsection{Demographic and Background Variables}

Background variables included six characteristics: child sex (male or female), parent education, low income family (poverty), ethnic group, length of time since arrival in Canada (years), and settlement region (Toronto or Montreal). Parent education (less than bachelor's degree or bachelor's degree/higher), was constructed as a dichotomized variable.

Family poverty was measured by the Low Income Cut-offs (LICO) of Statistics Canada based on total household income during the 12 months prior to the interview. Canada has no official poverty measure and the LICO is a relative measure based on family size and community size (Lightman, 2003). For the purpose of this study (focusing on family poverty), data for the family income level were re-coded by the LICO: families with the adjusted income below $75 \%$ of the LICO were classified as living in poverty. This definition includes a 
correction of income level for both family size and place of residence. A household income above $75 \%$ of the LICO was coded as above poverty line, and a household income below $75 \%$ of the LICO was coded as below the poverty line. To retain cases with income missing data and to avoid uncertain assumptions of imputed data, another category for income not reported was created (Beiser et al., 2010). Among the three categories, above poverty line was used as the reference group in regression models.

Ethnic group is considered as a proxy measure in the current study as it is the marker that differentiates one group from the other group in terms of their history, social and cultural heritage. To control for ethnic heterogeneity, two dummy variables were included in the regression models: Hong Kong and Philippines. Among three ethnic groups, Mainland Chinese group was used as the reference category because it represents the largest group of immigrants in Canada (Statistics Canada, 2008).

\section{Statistical Analyses}

Descriptive analyses of the frequencies and means of all study variables were first performed to describe the sample and characteristics. Bivariate analyses (independent-samples t-tests and Chi-square tests) were used to compare mean/sampling distribution differ- ences of predictors and outcome variables between the two settlement regions, Toronto and Montreal. In addition, Pearson Correlation was performed for the bivariate correlations between dependent variables and each of the predictors.

To address the study objectives, a series of multiple regression models were tested for each of the three dependent variables. They examined the effects of children's experiences of inclusion and exclusion (inclusive school environment, social isolation, psychological isolation, perceived peer discrimination, and perceived teacher discrimination) on their developmental outcomes (self-esteem, social competence, and academic grades), controlling for background variables.

\section{Results}

Descriptive statistics for demographic and socioeconomic characteristics are given in Table 1 . The sample consisted of $49.5 \%$ males and $50.5 \%$ females. $60.0 \%$ of PMK (mostly the mother) had a bachelor's degree. Based on the family income, $44.4 \%$ of the immigrant families lived in poverty. The percentages of ethnic origin were $40.2 \%$ for Mainland China, $28.9 \%$ for Hong Kong, and $30.9 \%$ for the Philippines. Average length of time in Canada was 4.3 years. The percentages of settlement region were $50.1 \%$ for Toronto and $49.9 \%$ for Montreal.

Table 1. Descriptive statistics of study variables.

\begin{tabular}{|c|c|c|c|c|}
\hline & & Mean/Total Scores Percentage & S.D. & Range \\
\hline \multicolumn{5}{|c|}{ Background variables } \\
\hline \multicolumn{2}{|c|}{ Child sex (female) } & $50.5 \%$ & & \\
\hline \multicolumn{2}{|c|}{ PMK education (bachelor's degree) } & $60.0 \%$ & & \\
\hline \multicolumn{2}{|c|}{ Family income (poverty) } & $44.4 \%$ & & \\
\hline \multirow{3}{*}{$\begin{array}{l}\text { Ethnic } \\
\text { group }\end{array}$} & Mainland Chinese & $40.2 \%$ & & \\
\hline & Hong Kong Chinese & $28.9 \%$ & & \\
\hline & Filipino & $30.9 \%$ & & \\
\hline \multicolumn{2}{|c|}{ Length of time (years) } & 4.33 & 3.15 & $1-13$ \\
\hline \multicolumn{2}{|c|}{ Settlement region (Montreal) } & $49.9 \%$ & & \\
\hline \multicolumn{5}{|c|}{ Predictor variables } \\
\hline \multicolumn{2}{|c|}{ School inclusion } & 17.04 & 2.85 & $0-24$ \\
\hline \multicolumn{2}{|c|}{ Social isolation } & $18.9 \%$ & & \\
\hline \multicolumn{2}{|c|}{ Psychological isolation } & 0.85 & 0.94 & $0-4$ \\
\hline \multicolumn{2}{|c|}{ Perceived peer discrimination } & 0.81 & 1.42 & $0-8$ \\
\hline \multicolumn{2}{|c|}{ Perceived teacher discrimination } & 1.54 & 2.32 & $0-12$ \\
\hline \multicolumn{5}{|c|}{ Dependent variables } \\
\hline \multicolumn{2}{|c|}{ Self-esteem } & 8.57 & 2.73 & $0-12$ \\
\hline \multicolumn{2}{|c|}{ Social competence } & 11.57 & 2.45 & $0-16$ \\
\hline \multicolumn{2}{|c|}{ Academic performance (grades) } & 8.44 & 1.34 & $4-10$ \\
\hline
\end{tabular}


Table 2 shows mean/total scores and proportions for each of the study variables including demographic background variables, predictors and outcome variables, by settlement region. Significant differences were found for family income (poverty), ethnic group, inclusive school environment, and social isolation. The results indicated that more than half of the Montreal sample $(53.2 \%$ ) lived in poverty (a household income below $75 \%$ of the LICO), as comparing with $35.9 \%$ of the Toronto sample. For the percentage of ethnic group, the Montreal sample included higher proportion of mainland Chinese group (45.5\%), compared to $34.9 \%$ in the Toronto sample. The scale scores for the inclusive school environment were significantly different between the two settlement regions; the Toronto sample reported a higher level of inclusive school environment than did the Montreal sample. Immigrant children from the greater Montreal area scored higher than children from the greater Toronto area on social isolation. Perceived peer discrimination was marginally significant $(p<0.10)$ although this did not reach the .05 level of statistical significance. Montreal immigrant children reported higher scores of perceived peer discrimination than did Toronto immigrant children.

Due to significant regional differences in poverty and ethnic group among the background variables as presented in Table 2, subsequent multivariate analyses were conducted (not provided in table) to take those regional effects into account. After controlling for background variables (child sex, parental education, poverty, ethnic group, and length of years), regional differences in three predictor variables remained significant in the same directions: inclusive school environment $(F[8,513]=8.018, p<.01)$; social isolation $\left(X^{2}\right.$ $[d f=8]=7.307, p<.01)$; peer discrimination $(F[8,498]$ $=1.345, p<.05)$. No significant regional differences in outcome variables were found.

A correlation matrix between the predictors and dependent variables is illustrated in Table 3. Inclusive school environment was positively correlated with children's social competence. Social isolation was negatively correlated with academic grades. Psychological isolation and perceived teacher discrimination were negatively correlated with all psychosocial functioning variables and academic grades. A negative correlation was also found between perceived peer discrimination and self-esteem as well as social competence.

Multiple regression analyses were performed to determine the relationship between the predictor variables and children's outcome variables. Table 4 illustrates the associations of inclusive school environment, social/psychological isolation, perceived discrimination, with psychosocial functioning and academic grades, controlling for the background variables.

Table 2. Study variables by settlement region.

\begin{tabular}{|c|c|c|c|c|}
\hline \multirow[t]{2}{*}{ Variables } & \multicolumn{2}{|c|}{ Mean/Total Scores or Percentage } & \multirow{2}{*}{$\begin{array}{l}\text { Statistical Test } \\
\text { ( } t \text { or } X^{2} / \text { Fisher's } \\
\text { Exact Test) }\end{array}$} & \multirow[t]{2}{*}{$P$-Value } \\
\hline & Toronto & Montreal & & \\
\hline \multicolumn{5}{|l|}{ Background variables } \\
\hline Child sex (female) & $49.6 \%$ & $51.4 \%$ & 2-sided & $p=.725$ \\
\hline PMK education (bachelor's degree) & $63.2 \%$ & $56.8 \%$ & 2-sided & $p=.151$ \\
\hline Family income (poverty) & $35.9 \%$ & $53.2 \%$ & 2-sided & $p=.000 * * *$ \\
\hline Mainland Chinese & $34.9 \%$ & $45.5 \%$ & & \\
\hline Ethnic Group Hong Kong Chinese & $33.7 \%$ & $24.1 \%$ & $x^{2}=7.71$ & $p=.021^{*}$ \\
\hline Filipino & $31.4 \%$ & $30.4 \%$ & & \\
\hline Length of time (years) & 4.37 & 4.29 & $t=.28$ & $p=.783$ \\
\hline \multicolumn{5}{|l|}{ Predictor variables } \\
\hline School inclusion & 17.42 & 16.65 & $t=3.10$ & $p=.002 * *$ \\
\hline Social isolation & $13.9 \%$ & $24.4 \%$ & 2-sided & $p=.005^{* *}$ \\
\hline Psychological isolation & .91 & .78 & $t=-1.59$ & $p=.113$ \\
\hline Perceived peer discrimination & .70 & .92 & $t=-1.76$ & $p=.083$ \\
\hline Perceived teacher discrimination & 1.61 & 1.48 & $t=.55$ & $p=.541$ \\
\hline \multicolumn{5}{|l|}{ Dependent variables } \\
\hline Self-esteem & 8.70 & 8.45 & $t=-1.06$ & $p=.288$ \\
\hline Social competence & 11.61 & 11.53 & $t=.36$ & $p=.717$ \\
\hline Academic performance & 8.48 & 8.40 & $t=.69$ & $p=.491$ \\
\hline
\end{tabular}

Note: ${ }^{*} p<.05,{ }^{* *} p<.01,{ }^{* * *} p<.001$. 
Table 3. Correlations between predictor variables and dependent variables.

\begin{tabular}{|c|c|c|c|c|c|c|c|c|}
\hline & 1. & 2. & 3. & 4. & 5. & 6. & 7. & 8. \\
\hline 1.School inclusion & - & & & & & & & \\
\hline 2.Social isolation & .027 & - & & & & & & \\
\hline 3.Psychological isolation & -.068 & $.105^{*}$ & - & & & & & \\
\hline 4.Peer discrimination & -.059 & -.019 & $.210 * * *$ & - & & & & \\
\hline 5.Teacher discrimination & -.036 & -.041 & $.210 * * *$ & .089 & - & & & \\
\hline 6.Self-esteem & .041 & -.052 & $-.160 * * *$ & $-.150 * *$ & $-.165^{* * *}$ & - & & \\
\hline 7.Social competence & $.143^{* * *}$ & -.046 & $-.290 * * *$ & $-.218^{* * *}$ & $-.185^{* * *}$ & $.309 * * *$ & - & \\
\hline 8.Academic performance & .034 & $-.115^{*}$ & $-.114^{*}$ & -.073 & $-.186 * * *$ & $.226 * * *$ & $.099 *$ & - \\
\hline
\end{tabular}

Note: ${ }^{*} p<.05, * * p<.01, * * * p<.01$ (two-tailed tests).

Table 4. Regressions of psychosocial functioning and academic performance on predictor variables.

\begin{tabular}{|c|c|c|c|c|c|c|c|c|c|}
\hline & \multicolumn{3}{|c|}{ Self-esteem } & \multicolumn{3}{|c|}{ Social Competence } & \multicolumn{3}{|c|}{ Academic Performance } \\
\hline & B & $B$ & S.E. & B & $B$ & S.E. & B & $B$ & S.E. \\
\hline \multicolumn{10}{|l|}{ Background variables } \\
\hline Sex(female) & -.196 & -.036 & .260 & .392 & .079 & .221 & $.357 * *$ & .132 & .124 \\
\hline PMK education & .032 & .006 & .326 & .135 & .027 & .275 & .073 & .027 & .153 \\
\hline Poverty & .167 & .030 & .295 & .403 & .080 & .248 & -.197 & -.072 & .139 \\
\hline Hong Kong & -.266 & -.044 & .506 & $.959 *$ & .176 & .427 & $-.929 * * *$ & -.312 & .240 \\
\hline Filipino & -.210 & -.035 & .343 & $.620 *$ & .114 & .291 & $-.897 * * *$ & -.299 & .165 \\
\hline Length of time & .077 & .085 & .063 & .003 & .003 & .053 & .021 & .049 & .030 \\
\hline Region(Montreal) & -.248 & -.045 & .280 & .176 & .036 & .238 & -.064 & -.024 & .133 \\
\hline \multicolumn{10}{|l|}{ Predictor variables } \\
\hline School inclusion & .013 & .013 & .048 & $.108 * *$ & .125 & .041 & $.046 *$ & .097 & .023 \\
\hline Social isolation & -.324 & -.046 & .338 & -.177 & -.028 & .286 & $-.394^{*}$ & -.112 & .163 \\
\hline Psychological isolation & $-.455^{* *}$ & -.159 & .145 & $-.609 * * *$ & -.236 & .123 & -.050 & -.035 & .070 \\
\hline Peer discrimination & $-.196 *$ & -.104 & .092 & $-.265 * * *$ & -.156 & .078 & -.056 & -.061 & .044 \\
\hline Teacher discrimination & $-.132 *$ & -.112 & .059 & $-.139 * *$ & -.130 & .050 & $-.069 *$ & -.115 & .029 \\
\hline Constant & \multicolumn{2}{|c|}{$9.175 * * *$} & .956 & $9.784 * * *$ & & .815 & \multicolumn{2}{|c|}{$8.255^{* * *}$} & .454 \\
\hline$R^{2}$ & \multicolumn{3}{|l|}{.076} & \multicolumn{3}{|l|}{.186} & \multicolumn{3}{|l|}{.167} \\
\hline Adjusted $R^{2}$ & \multicolumn{3}{|l|}{.047} & \multicolumn{3}{|l|}{.161} & \multicolumn{3}{|l|}{.141} \\
\hline
\end{tabular}

Notes: Significant differences appear in boldface; ${ }^{*} p<.05^{* *} p<.01 * * * p<.001$.

The first regression model for self-esteem accounted for 4.7 percent of the variance. The results revealed that psychological isolation, peer discrimination and teacher discrimination made significant contributions to explaining variation in self-esteem scores. Children who were psychologically isolated were more likely to show low levels of self-esteem. Higher levels of perceived discrimination by peers and teachers were associated with lower levels of self-esteem

For the social competence scale, the predictor variables accounted for 16.1 percent of the variance. Inclusive school environment, psychological isolation, perceived discrimination by peers and teachers were highly significant in relation to social competence. Higher levels of inclusive school environment were associated with greater social competence. Psychological isolation was negatively related to social competence. Immigrant children perceiving more discrimination by peers and teachers rated themselves as being less socially competent.

The last regression model for child academic adjustment measured by academic grades accounted for
14.1 percent of the variance. Inclusive school environment, social isolation, and perceived teacher discrimination were significant in relation to academic grades. The effect of inclusive school environment was positively related to academic grades. Social isolation was significantly associated with academic grades, indicating that children who felt socially isolated were more likely to show lower academic grades. Among demographic variables, child sex and ethnic group made significant contributions to academic grades. Females reported higher scores of academic grades than males. Immigrant children from the Mainland Chinese group scored higher than children from the Hong Kong and the Filipino groups on academic grades.

\section{Discussion and Conclusion}

This article has been guided by the research objectives concerning the potential inclusion and exclusion factors of immigrant children in school settings, and the relationships between these factors and children's out- 
comes. Overall the findings demonstrate that the experiences of inclusion and exclusion contribute to children's psychosocial and academic adjustment.

Participating in social group activities significantly increase peer interactions and social acceptance in terms of social inclusion, as revealed by the study on Canadian children (Canadian Council on Social Development, 2002). Positive peer interactions and affective bonds established by children in social groups can play an important role in determining children's better outcomes. The results of our study indicated that the experience of social group disengagement was significantly associated with low levels of academic grades, but not with psychosocial adjustment. The link between social group participation and academic adjustment is supported by an Asian immigrant children's study (Zhou \& Kim, 2006) showing that the academic success stems in large part from the role of the social groups, providing positive academic behaviour and aspiration. For newly arrived immigrant students, forming the companionship in social groups seems to be especially important, since these peers can serve as significant sources of information on school culture and orientation, which leads to positive school adaptation and better academic performance (Suarez-Orozco et al., 2009). In many cases, however, participating in organized social groups requires parents' financial support that is often lacking in recent immigrant families. Moreover, because of immigrant parents' lack of time and lack of knowledge of social activities for their children, foreign-born parents are less likely to become involved in their children's social lives. It is required for school professionals to provide new and different strategies for grouping children to facilitate immigrant children's peer interactions and develop social skills. A limitation in our study is the lack of distinction between involvement in different types of social groups such as academically oriented-groups vs. recreational activity groups, or co-ethnic community groups vs. mainstream social groups. Future research needs to examine how various social groups would influence differentially immigrant children and whether they positively or negatively impact children's outcomes.

Immigrant children also need to overcome important psychological aspects of exclusion. Our research found that psychological isolation was a significant exclusion factor in understanding the psychosocial adjustment of immigrant children, showing that psychological isolation was associated with low selfesteem and less social competence. For immigrant children, a sense of acceptance or a feeling of inclusion within the school community is a crucial part of their successful adaptation process since they have unique characteristics related to ethnicity and race as demonstrated by previous studies (Micklewright, 2002; Suarez-Orozco \& Suarez-Orozco, 2001). Immigrant status, unfavorable economic status, and discrimination may provide additional challenges to form their potential friendships, compared to native-born children. They may have also limited access to supportive adults in schools. Teachers and school staff may be ill-equipped with the culturally sensitive skills and knowledge needed to work with diverse immigrant students. There is some research evidence that the presence of teachers with minority group backgrounds has a positive influence on minority student achievement (Schofield, 2006). School policies would benefit by recruiting teachers with ethnically diverse backgrounds in order to decrease the cultural distance between immigrant students and school, and to raise the educational opportunities of minority students.

Our study found that perceived discrimination at school was an important predictor of psychosocial and academic adjustment. The results suggest that discrimination by peers can constitute a critical source of social exclusion for immigrant children affecting negatively their outcomes. In particular, perceived peer discrimination based on ethnicity and migration backgrounds was associated with decreasing the likelihood of displaying self-esteem and social competence. This finding is supported by previous studies on immigrant children (Graham, 2006; Oxman-Martinez et al., 2012) highlighting the possibility of exclusion by peers that might result in impairing the development of friendships and decreasing self-esteem. The current study also found the link between perceived teacher discrimination and children's outcomes; the perception of teachers' discriminatory attitudes was significantly related to poor psychosocial adjustment as well as lower academic grades. Based on these findings, teachers can also be a potential agent of exclusion through failure to treat their students fairly regardless of their ethnic backgrounds. As an anti-discrimination policy within the school context that combats the obstacles hindering more participation and higher educational achievement of students from ethnic minorities, it is expected that initial teacher education and training programs such as integration and intercultural education for new teachers in multi-ethnic schools, should prepare teachers adequately for treating and teaching immigrant children.

The results showed that the parental perception of school environment was significantly related to children's social competence and academic grades, but not to self-esteem. These findings are consistent with relatively similar results of previous research (Hamilton et al, 2011) that negative immigrant parental perceptions of school environment influence children's maladjustment-emotional distress and behavioural problems. Since there is a paucity of research on the link between parental perceptions of school environment and children's outcomes, our findings add new empirical evidence regarding positive parental perceptions of school environment and children's healthy adjustment-social competence and academic grades. This 
result also implies that the possible dissonance between immigrant families and the educational environment may deepen parental disengagement in schools affecting negatively the children's psychosocial and academic adjustment (Carreon et al, 2005; Ramirez, 2003; Schofield, 2006). As immigrant parents often tend to feel powerless, alienated, and culturally estranged from their children's school (Carreon et al, 2005; Shor \& Bernhard, 2003), they need professional guidance and carefully structured programs to enhance effective ways to become more involved in the school lives of their children. Considering lack of language fluency, stresses of acculturation, and economic insecurity in particular during the beginning years of resettlement, outreach to immigrant parents should be a priority for schools: for instance, home visiting with involvement of co-ethnic community organizations and communication with parents in either their mother tongues or official languages.

When examining variations between the two settlement regions, we found significant differences in children's experiences of social isolation and peer discrimination, and parental perceptions of school environment while not in outcome variables. The regional differences in three predictor variables remained significant in the same directions even after controlling for demographic background variables. In our study sample, children from the Montreal region as compared with those from Toronto were more likely to show higher levels of social isolation and perceived peer discrimination. Moreover, Montreal parents also reported lower levels of inclusive school environment than those from Toronto. These results are less positive for the Montreal immigrant group. These findings may be related to differential official language requirements between Quebec and Ontario provinces: French and English, respectively. As the current study sample contains three Asian immigrant groups, Quebec's linguistic policy may magnify adaptation difficulties and resettlement stresses for Montreal immigrant children and their parents, in spite of compulsory French immersion classes. In Quebec, the educational provisions of the Charter of the French Language (Bill 101) in 1977 established the attendance of French language schools as the norm for all students including immigrant children (Driedger, 2003; McAndrew, 2004). One of the Charter's articles stipulates that all children under 16 must receive their primary and secondary education in French schools, unless one of the child's parents has received most of their education in English, in Canada, or the child has already received a substantial part of his/her education in English, in Canada. With respect to social isolation and peer discrimination, immigrant children are more likely to be at higher risk because of language barriers, language-dependent social skills and cultural norms such as initiating prosocial interactions and setting limits or boundaries with peers. Children's ability to communicate effectively with peers is related to their language ability as well as their social behaviour such as their interactions with peers that either promote or hinder the development of healthy peer relationships (Von, Kochenderfer-Ladd, Perren, \& Alsaker, 2010). For immigrant parents, insufficient proficiency in an official language may be the main barrier to both parental participation in children's socialization and involvement in children's schools. Implications raised from this issue for school professionals are related to the need to help immigrant children adapt better to their school settings by providing additional language means and social supports. As well, the services are required both for immigrant parents and teachers (in-service training): for instance, translation, interpretation, counselling and techniques for including newly-arrived parents in the education of their children.

Our results also showed that despite the presence of risk factors-social isolation, perceived peer discrimination, and lower levels of inclusive school perceptions, the Montreal immigrant children in our sample demonstrated no significant differences in the outcome variables as compared to their counterpart in Toronto. It seems that children in the Montreal group have protective or resilience factors contributing to psychosocial and academic adjustment. Further longitudinal research of the NCCYS is needed to explore protective factors to produce positive outcomes for those immigrant children who live under negative circumstances.

There are some limitations that should be noted. First, as the study results are based on cross-sectional data, the direction of causal relationships between study variables cannot be determined. Future longitudinal analyses with wave 2 data of the NCCYS should disentangle the direction of variable effects. Second, sample groups were recruited from the specific regions of the Greater Montreal in Quebec and Toronto in Ontario where the educational systems and structures are different from the other Canadian provinces. Thus, the findings must be interpreted with caution to the wider Canadian context. In addition, although we found many significant relationships between variables in our regression models in key areas of important child outcomes, the amount of variance explained varies only from about $5 \%$ to $16 \%$, leaving a great deal of variance unaccounted for. Lastly, this study did not include school demographic variables such as majority or minority ethnic concentration and the number of minority group teachers. These school characteristics may have different consequences according to whether they bring social cohesion and mutual support or social disorganization within educational settings. Future research needs to consider these features of school environment.

In an ethnically diverse society, the phenomenon of ethno-cultural, linguistic and religious diversity characterizes the education systems of Canada. Formal schooling and educational-related issues have become more important in wider political discussions and 
strategies regarding inclusion and exclusion, particularly with respect to children with diverse ethnic backgrounds. Educational institutions need to find ways to accommodate this diversity in their educational policies and practices. It is necessary that educational settings should develop a systematic effort to increase a better understanding of different cultures, a greater capacity to communicate with those from other cultures, along with positive attitudes toward other groups among both the majority and the minority.

\section{Acknowledgments}

This paper is a product of the New Canadian Children and Youth Study (Principal Investigators: Morton Beiser, Robert Armstrong, Linda Ogilvie, Jacqueline OxmanMartinez, Joanna Anneke Rummens), a national longitudinal survey of the health and well-being of more than 4,000 newcomer immigrant and refugee children living in Montreal, Toronto, Winnipeg, Edmonton, Calgary and Vancouver. The NCCYS is a joint collaboration between university researchers affiliated with Canada's four Metropolis Centres of Excellence for research on immigration and settlement, and community organizations representing Afghani, Hong Kong Chinese, Mainland Chinese, Latin American (Salvadorian, Guatemalan, Colombian), Ethiopian, Haitian, Iranian, Kurdish, Lebanese, Filipino, Punjabi, Serbian, Somali, Jamaican, Sri Lankan Tamil, and Vietnamese newcomers in Canada. The NCCYS team is comprised of: investigators from eight universities representing multiple disciplines and involving faculty and trainees at various levels; research associates; immigrant/refugee community advisors representing sixteen immigrant communities; plus a research staff comprised of post-doctoral trainees, national coordinators, site coordinators, research assistants and numerous interviewers at each site. Major funding for the project has been provided by the Canadian Institutes of Health Research (CIHR grants FRN-43927 and PRG80146), Canadian Heritage, Citizenship and Immigration Canada (CIC), Health Canada, Justice Canada, Alberta Heritage Foundation for Medical Research, Alberta Learning, B.C. Ministry of Social Development and Economic Security, B.C. Ministry of Multiculturalism and Immigration, Fonds de Recherche du Québec: Société et Culture (FRQ-SC), Manitoba Labour and Immigration, OASIS (CIC), the Ontario, Prairies and Quebec Metropolis Centres of Excellence for research on immigration and settlement, and the Ontario Mental Health Foundation.

\section{Conflict of Interests}

The authors declare no conflict of interests.

\section{References}

Ainscow, M. (1999). Understanding the development of inclusive schools. London, UK: Falmer Press.

Alain-Gustave, G., \& lacovino, R. (2008). Federalism, citizenship, and Quebec: Debating multinationalism. Toronto, ON: University of Toronto Press.

Barett, M. (2014). Interculturalism and multiculturalism: Similarities and differences. Strasbourg: Council of Europe.

Beiser, M., Hamilton, H., Rummens, J. A., OxmanMartinez, J., Ogilvie, L., Humphrey, C., \& Armstrong, R. (2010). Predictors of emotional problems and physical aggression among children of Hong Kong Chinese, Mainland Chinese and Filipino immigrants to Canada. Social Psychiatry and Psychiatric Epidemiology, 45, 1011-1021.

Beiser, M., Lancee, W., Gotowiec, A., Sack, W., \& Redshirt, R. (1993). Measuring self-perceived role competence among First Nations and non native children. Canadian Journal of Psychiatry, 38, 412-419.

Bouchard, G., \& Taylor, C. (2008). Building the future: $A$ time for reconciliation. Québec: Gouvernement de Québec.

Broderick, P. C., \& Blewitt, P. (2006). The life span: Human development for helping professionals. Upper Saddle River, NJ: Pearson Education.

Brown, R., Baysu, G., Cameron, L., Nigbur, D., Rutland, A., Watters, C., Hossain, R., Le Touze, D., \& Landau, A. (2013). Acculturation attitudes and social adjustment in British South Asian children: A longitudinal study. Personality and Social Psychology Bulletin, 39(12), 1656-1667.

Canadian Council on Social Development. (2002). The progress of Canada's children. Ottawa, ON: Canadian Council on Social Development.

Carreon, G. P., Drake, C., \& Barton, A. C. (2005). The importance of presence: Immigrant parents' school engagement experiences. American Educational Research Journal, 42, 465-498.

Chen, X., Chang, L., He, Y., \& Liu, H. (2005). The peer group as a context: Moderating effects on relations between maternal parenting and social and school adjustment in Chinese children. Child Development, 76(2), 417-434.

Chui, T., Tran, K., \& Maheux, H. (2007). Immigration in Canada: A portrait of the foreign-born population, 2006 census (Catalogue No. 97-557-XIE). Ottawa, ON: Statistics Canada.

Citizenship and Immigration Canada. (n.d.). CanadaQuébec Accord relating to immigration and temporary admission of aliens. Retrieved from http:// www.cic.gc.ca/EnGLish/department/laws-policy/ag reements/quebec/can-que.asp

Citizenship and Immigration Canada. (2006). Facts and figures: Immigration overview: Permanent residents. Ottawa, ON: Citizenship and Immigration Canada.

Crosnoe, R., Johnson, M. K., \& Elder, G. H. (2004). Intergenerational bonding in school: The behavioural and contextual correlates of student-teacher rela- 
tionships. Sociology of Education, 77(1), 60-81.

Davison, A. R. M., Guerrero, M. P., Barajas, H. H., \& Thomas, G. (1999). Perceptions of Chicano/Latino students who have dropped out of school. Journal of Counseling \& Development, 77(4), 465-473.

De Haan, A. (1999). Social exclusion: Towards a holistic understanding of deprivation. London, UK: Department for International Development.

Dei, G. J., Sefa, I. M. J., Leeno, L. K., Sonia, J. W., \& Jasmine, Z. (2000). Removing the margins: The challenges and possibilities of inclusive schooling. Toronto, ON: Canadian Scholars' Press.

Driedger, L. (2003). Language and the Quebecois nation. In L. Driedger (Ed.), Race and ethnicity: Finding identities and equalities (pp. 94-118). Don Mills, ON: Oxford University Press.

DuBois, D. L., \& Silverthorn, N. (2005). Natural mentoring relationships and adolescent health: Evidence from a national study. American Journal of Public Health, 95(3), 518-524.

Duffy, A. (2003). Class struggles: Public education and the new Canadian. Toronto, ON: Atkinson Foundation.

Evans, P., Suzanne, B., John, B., Stephan, K., Phyllis, M., \& Stewart, R. (May, 2001). Social exclusion and children. Creating identity capital: Some conceptual issues and practical solutions. Presented at the Conference on Social Exclusion and Children, The Institute for Child and Family Policy, Columbia University, USA.

Fisher, C. B., Wallace, S. A., \& Fenton, R. E. (2000). Discrimination distress during adolescence. Journal of Youth and Adolescence, 29, 679-695.

Frazee, C. (2003). Thumbs up! Inclusion, rights and equality experienced by youth with disabilities. Toronto, ON: Laidlaw Foundation.

Fuligni, A. J. (1998). Adolescents from immigrant families. In V. C. McLoyd \& L. Steinberg (Eds.), Studying minority adolescents: Conceptual, methodological, and theoretical issues (pp. 127-143). Mahwah, NJ: Lawrence Erlbaum Associates.

Gibson, M., Gandara, P., \& Koyama, J. P. (2004). School connections: U.S. Mexican youth, peers, and school adjustment. New York: Teacher's College Press.

Government of Canada. (n.d.). Constitution Act of 1867: 30 \& 31 Victoria, c. 3 (U.K.). Retrieved from http:// laws-lois.justice.gc.ca/eng/Const/page-1.html

Graham, S. (2006). Peer victimization in school: Exploring the ethnic context. Current Directions in Psychological Science, 15(6), 317-321.

Hamilton, H. A., Marshall, L., Rummens, J. A., Fenta, H., \& Simich, L. (2011). Immigrant parents' percpetions of school environment and children's mental health and behavior. Journal of School Health, 81, 313-319.

Jackson, A., \& Scott, K. (2002). Does work include children? The effects of the labour market on family income, time and stress. Toronto, ON: Laidlaw Foundation.

Juvonen, J., \& Graham, S. (2001). Peer Harassment in school: The plight of the vulnerable and the victim- ized. New York, NY: Guilford.

Klasen, S. (2000). Social exclusion, children, and education: Conceptual and measurement issues. Paper for OECD expert seminar on childhood social exclusion, Department of Economics, University of Munich, Germany. Retrieved from http://www.oecd.org/ education/innovation-education/1855901.pdf

Kochenderfer, B. J., \& Ladd, G. W. (1996). Peer victimization: Cause or consequence of school maladjustment. Child Development, 67(4), 1305-1317.

LaRusso, M. D., Romer, D., \& Selman, R. L. (2008). Teachers as builders of respectful school climates: Implication for adolescent drug use norms and depressive symptoms in high school. Journal of Youth and Adolescence, 37(4), 386-398.

Leary, M. R., \& Baumeister, R. F. (2000). The nature and function of self-esteem: Sociometer theory. In M. P. Zanna (Ed.), Advances in experimental social psychology (vol. 32, pp. 1-62). San Diego, CA: Academic Press.

Lightman, E. (2003). Social Policy in Canada. Don Mills, ON: Oxford University Press.

Mansouri, F., \& Kamp, A. (2007). Structural deficiency or cultural racism: The educational and social experiences of Arab-Australian youth. Australian Journal of Social Issues, 42(1), 87-102.

Marsh, H. W. (1988). Self-description Questionnaire, SDQ Manual: the Psychological Corporation. New York, NY: Harcourt Brace \& Company.

McAndrew, M. (2004). Immigration, pluralism and education. In A. G. Gagnon (Ed.), Quebec: State and society (pp. 307-327). Toronto, ON, Canada: Broadview Press.

Mejer, L., \& Siermann, C. (2000). Income poverty in the European Union: Children, gender and poverty gaps. Luxembourg: Eurostat.

Micklewright, J. (2002). Social exclusion and children: $A$ European view for a US debate (Innocenti Working Paper 90). Florence, Italy: UNICEF.

Micklewright, J., \& Stewart, K. (2000). Child well-being in the EU and enlargement to the East (Innocenti Working Paper 75). Florence, Italy: UNICEF.

Ministry of Supply and Services. (1988). Report of the Canadian Task Force on mental health issues affecting immigrants and refugees. After the door has been opened (Catalogue. no. Ci96-38/1988E). Ottawa, ON: Ministry of Supply and Services. Retrieved from http://ceris.metropolis.net/Virtual\%20Library/ health/candian_taskforce/canadian1.html

Mounts, N. S., \& Steinberg, L. (1995). An ecological analysis of peer influence on adolescent grade point average and drug use. Developmental Psychology, 31, 915-922.

Nigbur, D., Brown, R., Cameron, L., Hossain, R., Landau, A., Le Touze, D., Rutland, A., \& Watters, C. (2008). Acculturation, well-being and classroom behavior among white British and British Asian primaryschool children in the south-east of England: Validating a child-friendly measure of acculturation at- 
titudes. International Journal of Intercultural Relations, 32, 493-504.

Oppendal, B., Espen, R., \& Heyerdahl, S. (2005). Ethnic group, acculturation, and psychiatric problems in young immigrants. Journal of Child Psychology and Psychiatry, 46(6), 646-660.

Oxman-Martinez. J., Rummens, A. J., Moreau, J., Choi, Y. R., Beiser, M., Ogilvie, L., \& Armstrong, R. (2012). Perceived ethnic discrimination and social exclusion: Newcomer immigrant children in Canada. American Journal of Orthopsychiatry, 82(3), 376-388.

Phipps, S., \& Curtis, L. (2001). The social exclusion of children in North America. Halifax, NS: Departments of Economics and Community Health and Epidemiology, Dalhousie University.

Ramirez, A. Y. F. (2003). Dismay and disappointment: Parental involvement of Latino immigrant parents. Urban Review, 35, 93-110.

Ridge, T. (2002). Childhood poverty and social exclusion: From a child's perspective. Bristol, UK: The Policy Press.

Roffman, J., Suárez-Orozco, C., \& Rhodes, J. (2003). Facilitating positive development in immigrant youth: The role of mentors and community organizations. In D. Perkins, L. M. Borden, J. G. Keith, \& F. A. Villaruel (Eds.), Positive youth development: Creating a positive tomorrow. Brockton, MA: Klewer Press.

Rong, K. L., \& Preissle, J. (1998). Educating immigrant students: What we need to know to meet the challenges. Thousand Oaks, CA: Corwin Press.

Rummens, J. A., Tilleczek, K., Boydell, K., \& Ferguson, B. (2008). Understanding and addressing early school leaving among immigrant and refugee youth. In $\mathrm{K}$. Tilleczek (Ed.), Why do students drop out of high school? Narrative studies and social critiques (pp. 75-101). New York, NY: Edwin Mellen Press.

Schofield, J. W. (2006). Migration background, minority-group membership and academic achievement: Research evidence from social, educational and developmental psychology. Berlin, Germany: Arbeitsstelle Interkulturelle Konflikte und Gesellschaftliche Integration (AKI).

Shor, R., \& Bernhard, J. K. (2003). A comparative study of conflict experienced between immigrant parents in Canada and in Israel, and professionals in educational institutions about appropriate responses to children's misbehaviour. Intercultural Education, 14(4), 385-396.

Spencer, M. B. (2001). Identity, achievement, orientation and race: Lesson learned about the normative developmental experiences of African American males. In W. Watkins, J. H. Lewis, \& V. Chou (Eds.), Race and education (pp.100-127). Needham Heights, MA: Allyn \& Bacon.

Spencer, M. B., Swanson, D. P., \& Cunningham, M. (1991). Ethnicity, Ethnic identity and competence formation: Adolescent transitions and identity transformation. Journal of Negro Education, 60(3), 366-387.

Statistics Canada. (2008). 2006 Census data products: Ethnic origin, 2006 counts for Canada (Catalogue No. 97-562-XWE2006002). Ottawa, ON, Canada: Statistics Canada.

Suarez-Orozco, C., Pimentel, A., \& Martin, M. (2009). The significance of relationships: Academic engagement and achievement among newcomer immigrant youth. Teachers College Record, 111(3), 712-749.

Suarez-Orozco, C., \& Suarez-Orozco, M. (2001). Children of Immigration. Cambridge, Massachusetts: Harvard University Press.

Suarez-Orozco, C., Suarez-Orozco, M., \& Todorova, I. (2008). Learning a new land: Immigration students in American society. Cambridge, MA: Harvard University Press.

United Nations Human Rights. (n.d.). Convention on the rights of the child. Retrieved from http://www. ohchr.org/en/professionalinterest/pages/crc.aspx

Verkuyten, M., Kinket, B., \& Wielen, C. V. (1997). Preadolescents' understanding of ethnic discrimination. The Journal of Genetic Psychology, 158(1), 97-112.

Von, G., Kochenderfer-Ladd, R. B., Perren, S., \& Alsaker, F. D. (2010). Links between local language competence and peer relations among Swiss and immigrant children: the Mediating role of social behavior. Journal of School Psychology, 50(2), 195-213.

Way, N., \& Phal, K. (2001). The predictors of friendship quality among ethnic minority, low-income adolescents. Journal of Research on Adolescence, 11, 325 349.

Zhou, M., \& Kim, S. (2006). Community forces, social capital and educational achievement: The case of supplementary education in the Chinese and Korean immigrant communities. Harvard Educational Review, 76(1), 1-29.

\section{About the Authors}

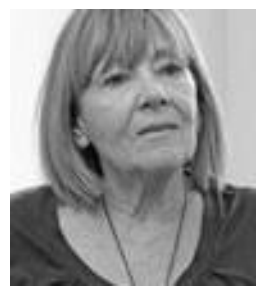

\section{Dr. Jacqueline Oxman-Martinez}

Jacqueline Oxman-Martinez holds a Ph.D. in Sociology of University of Montreal. She is an exResearch Associate at the Centre for Applied Family Studies, ex-Adjunct Professor of McGill University, School of Social Work and ex Research Associate at University of Montreal. She coordinated Component IV of the Immigration and Metropolis Centre of Excellence, the Montréal Centre for InterUniversity Research on Immigration and Integration in Urban Dynamics. Her research focuses on children and women's poverty and their wellbeing from cross-cultural and migration perspectives. 
Ye Ri Choi received her MSW from the McGill University, School of Social Work and she is currently completing a Ph.D. at McGill University. She is interested in the understanding of developmental pathways and competence of immigrant children and youth. Her research focuses on the effects of migration-related experiences on psychosocial adjustment among immigrant children and youth. She has worked for more than 10 years on the New Canadian Children and Youth Study (NCCYS). 